\title{
Treating Plasma Cell Myeloma in Developing Countries: Does Everyone Need the Newest Drugs?
}

\author{
Robert Peter Gale
}

Centre for Haematology, Department of Immunology and Inflammation, Imperial College London, London, UK

Editorial comment on the paper by Murieta-Álvarez
et al. Treatment of Persons with Multiple Myeloma
in Underprivileged Circumstances: Real-World
Data from a Single Institution. An Original Paper.
Acta Haematol 2020;143:552-558

In this issue of Acta Haematologica, Murrieta-Alvarez et al. [1] report on the results of plasma cell myeloma (PCM) therapy at an advanced cancer centre in Puebla Mexico where many anti-myeloma drugs, including dexamethasone, thalidomide, bortezomib, and lenalidomide, were available but many newer therapies such as pomalidomide, carfilzomib, xiazomib, and daratumumab were not. Moreover, not everyone had access to bortezomib and lenalidomide because the costs of these drugs are not covered by Mexico's national health insurance. Most younger individuals also received high-dose melphalan followed by an outpatient autotransplant using refrigerated (not frozen) blood cells. The excellent outcomes that these authors report raise the question whether everyone with PCM needs access to the newest drugs.

The authors offer several conclusions from their study: (1) the median survival of all subjects was 13 years; (2) the survival of subjects receiving or not receiving an autotransplant was similar; (3) although the response rate was higher for subjects receiving bortezomib added to dexamethasone and thalidomide, survivals were similar whether or not bortezomib was given; and (4) amongst autotransplant recipients, there was no difference in survival between those given posttransplant thalidomide compared with lenalidomide.

$\begin{aligned} & \text { karger@karger.com } \\ & \text { www.karger.com/aha }\end{aligned}$
Karger $\%$

To understand what these data mean, we should briefly consider variables of the Mexican economy. Mexico's population is about 126 million with a gross domestic product (GDP) of 1.221 trillion (2018; World Bank). The per capita gross nation income (GNI) is $\$ 9,180$ (USD; 2017), and the per capita GDP product is $\$ 20,245$ (USD; 2018; Organization for Economic Cooperation and Development [OECD]) [2]. Comparable data for the US are $\$ 60,200$ (GNI; USD; 2017) and $\$ 62,480$ (GDP; USD; 2018). Based on these data, the World Bank classifies Mexico as upper middle-income, the next to highest income category [3]. For example, 93\% of Mexicans have a mobile phone subscription compared with $35 \%$ of individuals globally and $67 \%$ in the US [4]. Also, the United Nations classify Mexico as a developing economy, somewhere between developed and in transition economies [5].

With these impressive economic data, why do most of us think of Mexico as a poor or under-developed country? My guess is that it reflects the mis-impression that wealth in Mexico is unevenly distributed: the richest $20 \%$ of individuals have $42 \%$ of the wealth whilst the poorest $10 \%$ of individuals have $<2 \%$. Mexico's Gini coefficient (a measure of wealth distribution) is 0.75 , placing it 122 of 164 countries and in the last place in the OECD [6]. The

Robert Peter Gale, MD, PhD, DSc (hc), FACP, FRCPI (hon), FRSM Centre for Haematology, Department of Immunology and Inflammation Imperial College London

London, SW7 2AZ (UK)

robertpetergale@gmail.com 
US, by comparison, has a Gini coefficient of 0.80 , worse than Mexico. Yet, we do not consider the US an underdeveloped or poor country compared say with Japan which has a Gini coefficient of 0.55 . For those more biologically orientated, hermit crabs have a Gini coefficient of 0.32 when it comes to sharing wealth (large abandoned snail shells to inhabit) [7]. It is estimated that the ideal human society would have a Gini coefficient of 0.33 [8]. We clearly have a way to go.

However, from a medical perspective, we need to consider per capita health care expenditures, not GNI, GDP, or Gini coefficient. Mexico's per capita health care spending is $\$ 460$ (USD; $5 \%$ of GDP) compared with about $\$ 11,000$ (USD) for the US (18\% of GDP), a 24 -fold difference. These data help put the Mexican health care system in perspective and explain why many new drugs for PCM are unavailable and/or unaffordable in Mexico.

There are several critical issues to consider when evaluating conclusions from an observational database such as that used by Murrieta-Alvarez et al. With a population of 120 million, I estimate about 10,000 new cases of PCM in Mexico every year after adjusting for race and age distribution. Therefore, in the 15 years covered in the typescript (1993-2008), I estimate that there were about 150,000 new cases of PCM in Mexico. Murrieta-Alvarez et al. report data on 108 subjects or about $0.07 \%$ of Mexicans developing PCM during this interval. We need go no further to conclude that their results are not representative of outcomes of PCM therapy in Mexico. However, other biases also operate including fiscal resources, willingness and ability to travel to Puebla, and others. When we evaluate conclusions from an observational database, we also need to consider statistical issues including consecutive reporting (claimed), data accuracy (independent auditing), completeness of follow-up, and other variables.

Next, a comment on nomenclature. PCM experts, including Murrieta-Alvarez et al., continue to refer to any drug developed since melphalan and prednisone as novel. Give me a break. The Oxford English Dictionary (OED, my Bible) defines novel as: "new and original, not like anything seen before". Thalidomide was approved for lepromatous leprosy by US FDA in 1998, 21 years ago and widely used off-label in the US until its approval for PCM in 2006, 14 years ago. It was not "new and original, not like anything seen before" if we consider its approval for morning sickness in Europe in 1956. We now have several newer IMiDs ${ }^{\circledR}$ including lenalidomide and pomalidomide. Bortezomib was approved by US FDA for PCM in 2003, 17 years ago. At that time, it was not like anything seen before. However, we now have several other protea- some inhibitors including carfilzomib and xiazomib. I admit daratumumab, approved by US FDA last year, is "new and original, not like anything seen before". My point is that there comes a time to stop calling every postmelphalan PCM drug novel.

The top line of this typescript is an excellent survival outcome: median survival of more than 13 years despite unavailability of many modern drugs. Contrast this with a median survival of persons with PCM in the US based on US Surveillance, Epidemiology, and End-Results Program (SEER) data of about 5.5 years or one-half that reported by Murrieta-Alvarez et al. and where many more therapy options are available. How to explain this discordance despite limited drug availability in Mexico, a 24fold lower per capita health care expenditure, etc.? The most obvious of many possibilities is selection biases. SEER covers 35 of the US population, a 500 -fold greater unbiased dataset compared with the Murrieta-Alvarez dataset covering $0.07 \%$ of the Mexican population, a 500 fold discordance. Another selection bias is age. Median age in the Murrieta-Alvarez dataset is $\mathbf{5 7}$ years, whereas median age in most developed countries is $65-70$ years. So, whilst we should applaud the excellent results reported by Murrieta-Alvarez et al., we should not assume that they apply to most individuals in Mexico with PCM or being confidently translated to other populations, developed or otherwise.

Lastly, how much confidence should we place in three other study conclusions: (1) survival of subjects receiving or not receiving an autotransplant was similar; (2) although response rate was higher for subjects receiving bortezomib added to dexamethasone and thalidomide than those not receiving it, survivals were similar; and (3) amongst autotransplant recipients, there was no difference in survival between those given posttransplant thalidomide compared with lenalidomide.

These questions are obviously best addressed in randomized clinical trials. First, survival of persons receiving or not receiving an autotransplant is similar. This was tested in many randomized clinical trials with convincing evidence of higher response rates, better event-free survival and survival ([9] for example). Second, adding bortezomib to dexamethasone and thalidomide does not improve survival. Again, this was tested in several randomized clinical trials all of which show better progression-free survival (PFS) and survival from adding bortezomib. Lastly, maintenance thalidomide and lenalidomide postautotransplant have similar survivals. There are no randomized trials testing this conclusion. However, several studies report better PFS but not survival with thalido- 
mide, whereas most data suggest better PFS and survival with lenalidomide [10-13].

I should add that these authors previously reported the possibility to use non-frozen haematopoietic cells for grafts in PCM and other diseases [14, 15]. Whether this is novel is debatable. I have recently discussed hominids storing bone marrow for up to 9 weeks in a cave in Israel 200,000-450,000 BCE [16]. Unfortunately, they failed to publish their data. I guess this is where the term publish or perish arises. Seen any hominids lately?

In summary, Murrieta-Alvarez et al. report data from an interesting observational database which inform our thinking about PCM therapy in developing countries where not every new drug is available and/or where only rich individuals can afford the newest drugs. Their outcomes are spectacular compared with most populationbased registries such as SEER. Unfortunately, we cannot know if their outcomes reflect selection biases, expert medical care, or a combination. Until we figure this out, let us try to get the other 149,892 individuals with PCM in Mexico to Puebla. I might go there myself if I get PCM. Even if outcomes are comparable, there is always mole poblano to feast on between therapy course.

\section{Disclosure Statement}

The author has no conflicts of interest to declare.

\section{References}

1 Murrieta-Álvarez I, Steensma D, OlivaresGazca JC, Olivares-Gazca M, Aurelio LeónPeña A, Cantero-Fortiz Y, et al. Treatment of persons with multiple myeloma in underprivileged circumstances: real-world data from a single institution. Acta Haematol. 2020. DOI 10.1159/000505606.

2 https://en.wikipedia.org/wiki/List_of_ OECD_countries_by_GDP_per_capita

3 https://datacatalog.worldbank.org/dataset/ gdp-ranking

4 https://internetinnovation.org/general/research-peek-of-the-week-smartphone-usersin-the-us-expected-to-reach-over-270-million-by-2020/

5 https://www.un.org/en/development/desa/ policy/wesp/wesp_current/2014wesp_ country_classification.pdf

6 https://en.wikipedia.org/wiki/List_of_ countries_by_distribution_of_wealth

7 Chase D, Douady R, Padilla DK. A comparison of wealth inequality in humans and nonhumans. Physica A. 2020;538:122962.
8 Demetrius L. Adaptive value, entropy and survivorship curves. Nature. 1978 Sep;275 (5677):213-4.

9 Attal M, Harousseau JL, Stoppa AM, Sotto JJ, Fuzibet JG, Rossi JF, et al. A prospective, randomized trial of autologous bone marrow transplantation and chemotherapy in multiple myeloma. Intergroupe Français du Myélome. N Engl J Med. 1996 Jul;335(2):91-7.

10 Stewart AK, Trudel S, Bahlis NJ, White D, Sabry W, Belch A, et al. A randomized phase 3 trial of thalidomide and prednisone as maintenance therapy after ASCT in patients with $\mathrm{MM}$ with a quality-of-life assessment: the $\mathrm{Na}$ tional Cancer Institute of Canada Clinicals Trials Group Myeloma 10 Trial. Blood. 2013 Feb;121(9):1517-23.

11 McCarthy PL, Holstein SA, Petrucci MT, Richardson PG, Hulin C, Tosi P, et al. Lenalidomide Maintenance After Autologous Stem-Cell Transplantation in Newly Diagnosed Multiple Myeloma: A Meta-Analysis. J Clin Oncol. 2017 Oct;35(29):3279-89.
12 Barosi G, Gale RP. Is lenalidomide the standard-of-care after an autotransplant for plasma cell myeloma? Leukemia. 2019 Mar;33(3): 588-96.

13 Ludwig H, Durie BG, McCarthy P, Palumbo A, San Miguel J, Barlogie B, et al.; International Myeloma Working Group. IMWG consensus on maintenance therapy in multiple myeloma. Blood. 2012 Mar;119(13):3003-15.

14 Ruiz-Argüelles GJ, Gale RP. Autotransplantations without cryopreservation. J Glob Oncol. 2018 Sep;4(4): 1.

15 Gale RP, Ruiz-Argüelles GJ. The big freeze may be over: a contracting universe for cryopreservation? Bone Marrow Transplant. 2018 Aug;53(8):947-8.

16 Gale RP, McCann SR. The not so new history of storing bone marrow. Bone Marrow Transplant. https://doi.org/10.1038/s41409-0190774-z. Epub 2019 Dec. 